\title{
Study of Epidemiology, Risk Factors and Clinical Spectrum for Neonatal Candidemia at Tertiary Care Hospital in North India
}

\author{
Baby*, Perbhat Kansal, Neerja Jindal, Renu Bansal and Sameer Singh Faujdar \\ Department of Microbiology, MM Medical College and Hospital Kumarhatti Solan, India \\ *Corresponding author
}

\section{A B S T R A C T}

\begin{tabular}{|l|}
\hline Ke y w or d s \\
$\begin{array}{l}\text { Candida, Neonates, } \\
\text { Candidemia, Risk } \\
\text { factors }\end{array}$ \\
\hline Article Info \\
\hline $\begin{array}{l}\text { Accepted: } \\
\text { 04 December } 2020 \\
\text { Available Online: } \\
\text { 10 January } 2021\end{array}$ \\
\hline
\end{tabular}

\section{Introduction}

Neonatal sepsis is acquired from the mother (vertical transmission) or nosocomially (horizontal transmission). Neonatal sepsis is divided into early onset sepsis (defined as onset of sepsis in the first three days of life) and late onset sepsis (after day three of life $)^{[1,2]}$. Candidemia refers to presence of fungi in blood and it associated with high morbidity and mortality. Candidemia in neonates is a serious problem and a common cause of late onset sepsis. Due to immature immune system, neonates are more vulnerable to invasive Candida infection ${ }^{[3,4]}$. Colonisation of hands of health care workers, skin and gastrointestinal tract of neonates is the first step in pathogenesis of candidemia. Various risk factors have previously identified in acquisition of neonatal candidemia, including prematurity, low birth weight, total parenteral nutrition, prolonged hospitalization, prolonged antibiotic therapy, intensive care unit (ICU) admission and invasive interventions ${ }^{[5,6]}$.

Now a days, candidemia has become a major cause of mortality in neonates in health care system due to presence of non specific signs and symptoms. Therefore the aim of present study was to evaluate incidence and epidemiology and to know about risk factors and clinical profile of candidemia in neonates. 


\section{Materials and Methods}

This descriptive study was conducted in the departments of Microbiology and Pediatrics of Guru Gobind Singh Medical College and Hospital, Faridkot, Punjab, India on neonates who were admitted in neonatal intensive care unit (NICU) with clinical suspicion of sepsis for a period of one and half year from March 2016 to August 2017. The study was approved by institutional research committee and institutional ethics committee. A total of 44 neonates with culture proven candidemia were admitted in NICU during the study period and were included in the study.

Information regarding name and central record number was recorded. Cases were analysed for presence of various risk factors for candidemia like gender, age at admission, birth weight, gestation age, prior use of antibiotics and antifungals, duration of hospital stay, intravenous catheterization, mechanical ventilation, any surgical intervention and referred from other places. Along with neonatal risk factors, maternal risk factors like mode of delivery, $\mathrm{h} / \mathrm{o}$ intrapartum use of antibiotics, h/o foul smelling liquor, h/o prolonged rupture of membranes, $\mathrm{h} / \mathrm{o}$ maternal fever, $\mathrm{h} / \mathrm{o}$ prolonged fever and h/o assisted delivery were also recorded. The clinical features like feed intolerance, poor cry, convulsions, apnea, temperature instability, irritability/lethargic were noted. Along with these all factors laboratory findings were also recorded and whole data was analysed.

\section{Statistical analysis}

Data was entered in Microsoft Excel and statistical analysis was done

\section{Results and Discussion}

During study period, total 426 consecutive blood cultures were received from NICU of
Guru Gobind Singh Medical College and Hospital, from clinically suspected cases of neonatal septicaemia. Out of these 426 blood cultures, 44 showed the growth of Candida. So we obtained isolation rate of Candida as $10.33 \%$ (44/426). We found that all the 44 species of Candida were non albicans. Out of these non albicans Candida spp., $40.91 \%$ were C. tropicalis, $34.09 \%$ were $C$. pelliculosa and $25 \%$ were C. krusei.

Out of these 44 neonates, $36.4 \%$ (16/44) had early onset and $63.6 \%$ (28/44) had late onset sepsis (Table 1). The difference between two was statistically significant $(\mathrm{p}=.0109)$. Out of 44 newborns selected for study, $70.5 \%$ were male neonates (Fig. 1).

At the time of admission, $56.8 \%$ (25) of neonates were having age between 0-7 days, 29.5\% (13) were having age between 8-14 days, $11.4 \%$ (05) were having age between 15-21 day and only 2.3\% (01) neonate having age $>21$ days (Fig. 2).

$33(75 \%)$ babies were have gestational age $<37$ weeks. There were 08 neonates with birth weight $>2.5 \mathrm{~kg}(18.2 \%), 18$ (41\%) belonged to $1.5-2.5 \mathrm{~kg}$ group, $12(27 \%)$ belonged to group $1-1.5 \mathrm{~kg}$ and only $06(13 \%)$ neonates were under $1 \mathrm{~kg}$ (Table 2).

Among the potential risk factors (Table 2) studied for neonatal candidemia- prior use of antibiotics and intravenous catheterization were most common (100\%), followed by referred from other places (47.72\%), prior antifungal use (29.5\%), mechanical ventilation $(22.7 \%)$, hospital stay $>15$ days (20.4\%) and any surgical intervention (4.5\%).

Of the various maternal risk factors observed, vaginal delivery was the most common $(52.2 \%)$, followed by $\mathrm{h} / \mathrm{o}$ intrapartum use of antibiotics (29.5\%), h/o foul smelling liquor $(18.2 \%), \mathrm{h} / \mathrm{o}$ prolonged rupture of membranes $(9.1 \%)$ and $\mathrm{h} / \mathrm{o}$ prolonged labour (4.5\%). 
While h/o assisted delivery and h/o maternal fever not found even in single case of neonatal candidemia (Fig. 3).

23 out of 44 newborns (52.2\%) had apnea during NICU stay and had cessation of respiration $>20$ seconds (Table 3 ).

Feed intolerance was observed in 35 out of 44 newborns $(79.5 \%)$, out of which $29(82.9 \%)$ neonates developed abdominal distension (Table 4). It was assessed by measuring abdominal girth.

Other clinical features observed in these 44 neonates were- lethargic $66 \%$ (29) and irritable $34 \%$ (15), presence of poor cry in
43.2\% (19) newborns and 13.6\% (06) babies develop convulsions during hospital stay.

Normal temperature of a neonates ranges from $36.5^{\circ} \mathrm{C}-37.4^{\circ} \mathrm{C}$. In our study, recorded temperature was $<36.5^{\circ} \mathrm{C}$ in $10(22.7 \%)$ neonates and $>37.4^{\circ} \mathrm{C}$ in $12(27.3 \%)$ neonates.

Thrombocytopenia was observed in 28 out of 44 neonates $(63.6 \%)$. Thrombocytopenia was defined as platelet count less than 1.5 lakh (Table 5).

Out of 44 neonates with candidemia, 28 neonates survived. So, overall survival of neonates was $63.6 \%$ in our study (Fig. 4).

Table.1 Distribution of neonates with candidemia according to the time of onset of sepsis $(n=44)$

\begin{tabular}{|c|c|c|}
\hline Time of onset of sepsis & Number & Percentage \\
\hline Early onset sepsis (EOS) $^{a}$ & 16 & $36.36 \%$ \\
\hline 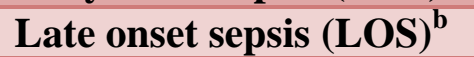 & 28 & $63.64 \%$ \\
\hline Total & 44 & $100.00 \%$ \\
\hline
\end{tabular}

Table.2 Potential risk factors of neonates with candidemia $(n=44)$

\begin{tabular}{|c|c|c|}
\hline Risk factor & Number & Percentage \\
\hline $\begin{array}{c}\text { Birth weight } \\
\text { Normal Birth Weight (>2.5 } \mathbf{~ k g})\end{array}$ & 08 & $18.18 \%$ \\
Low Birth Weight (LBW<2.5 kg) & 36 & $81.82 \%$ \\
\hline $\begin{array}{c}\text { Gestation period } \\
\text { Preterm(<37weeks) }\end{array}$ & 33 & $75.00 \%$ \\
Term (37 weeks) & 11 & $25.00 \%$ \\
\hline Prior use of antibiotics & 44 & $100.00 \%$ \\
\hline Intravenous catheterization & 44 & $100.00 \%$ \\
\hline Mechanical ventilation & 10 & $22.72 \%$ \\
\hline Any surgical intervention & 02 & $4.54 \%$ \\
\hline Prior antifungal use & 13 & $29.50 \%$ \\
\hline Referred from other places & 21 & $47.72 \%$ \\
\hline Duration of hospital stay & & \\
\hline$>15$ days & 09 & $20.45 \%$ \\
\hline
\end{tabular}


Table.3 Distribution of neonates on the basis of presence/absence of apnea $(n=44)$

\begin{tabular}{|c|c|c|}
\hline Presence of apnea & Number & Percentage \\
\hline Yes & 23 & $52.2 \%$ \\
\hline No & 21 & $47.8 \%$ \\
\hline
\end{tabular}

Table.4 Distribution of neonates on the basis of feed intolerance $(n=44)$

\begin{tabular}{|c|c|c|}
\hline Presence of feed intolerance & Number & Percentage \\
\hline Yes & 35 & $79.5 \%$ \\
\hline No & 09 & $20.5 \%$ \\
\hline
\end{tabular}

Table.5 Distribution of neonates on the basis of thrombocytopenia $(n=44)$

\begin{tabular}{|c|c|c|}
\hline Presence of thrombocytopenia & Number & Percentage \\
\hline Yes & 28 & $63.6 \%$ \\
\hline No & 16 & $36.4 \%$ \\
\hline
\end{tabular}

Fig.1 Sex distribution of neonates with candidemia

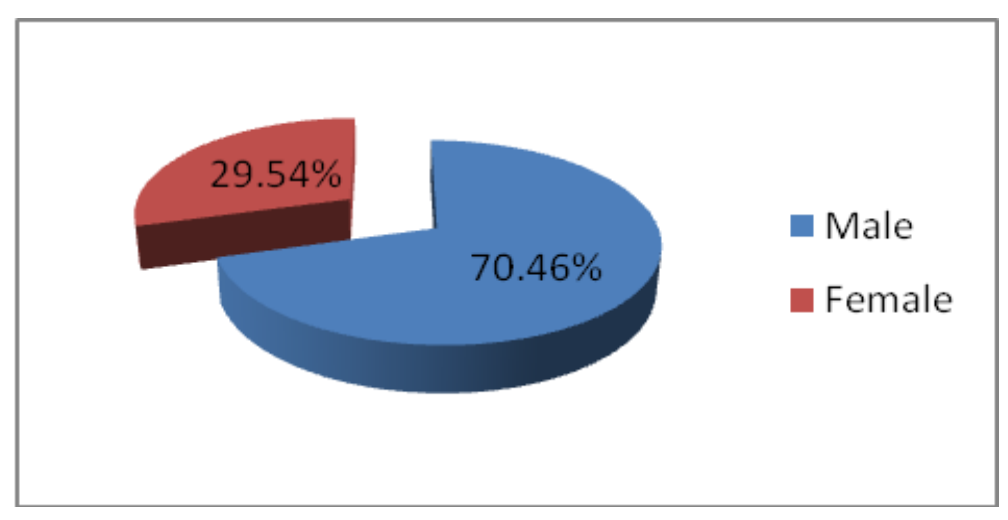

Fig.2 Age distribution of neonates with candidemia

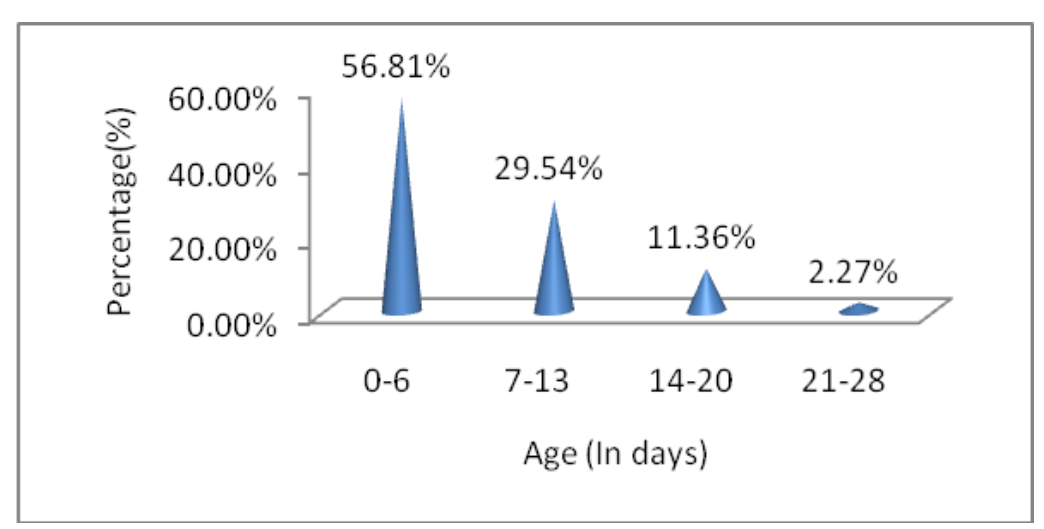


Fig.3 Maternal risk factors

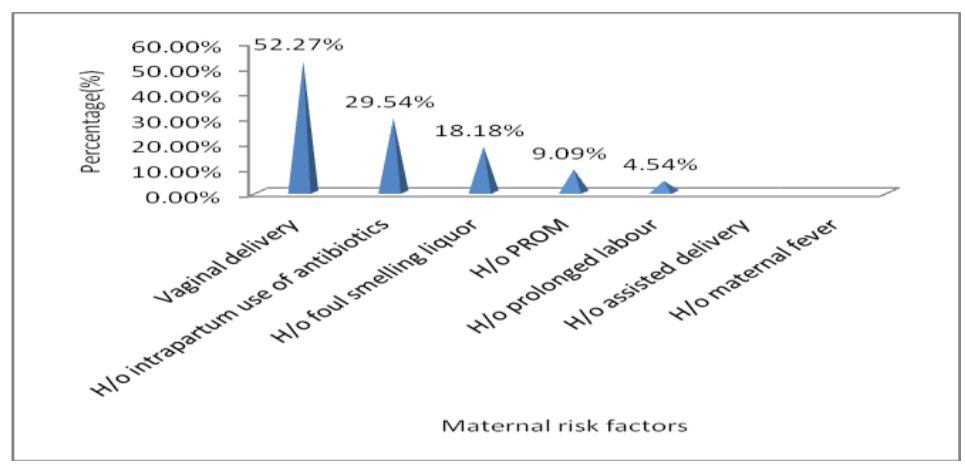

Fig.4 Final outcome of neonates with NAC spp. infection

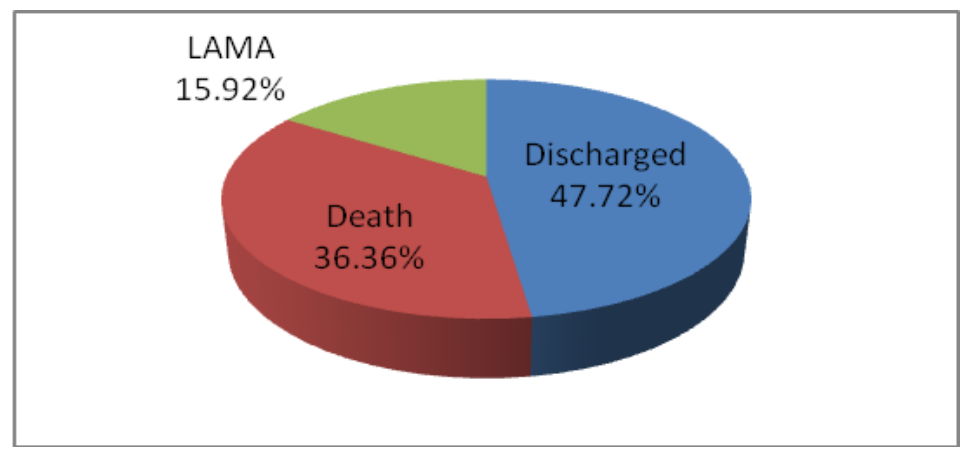

In NICU, infection with rare organisms is increasing day by day. In today's practice, due to advances in medical and surgical management, there is increase in rate of nosocomial fungal infection. Rate of neonatal candidemia has increased drastically during the past time, due to increase in rate of survival of low birth weight babies.

The isolation rate of neonatal candidemia varies from institution to institution and in the same institution it varies from time to time. In the present study, candidemia was found to be responsible for $10.33 \%$ cases of neonatal septicaemia which is consistent with the observations of Goel et al., ${ }^{[7]}$ and Benjamin et $a l^{[5]}$. However some authors have observed lower rates (1.5-4\%) of neonatal candidemia $^{(8,9)}$. This variation in isolation rate of Candida could be because of variability in the various risk factors in the study population. Of the 44 neonates with candidemia in the present study, majority 28 $(63.64 \%)$ presented with late onset sepsis and only $16(36.36 \%)$ had early onset sepsis, which is consistent with the findings of Caggiano et al., ${ }^{[10]}$ and Benjamin et al. ${ }^{[5]}$, they also reported candidemia as a third most common cause of late onset sepsis in NICU patients accounting for $9-13 \%$ of blood stream infection in neonates.

The reported mean age of onset of candidemia ranged between 15 to 33 days in earlier studies. ${ }^{[11,12]}$ In the present study, it was observed as early as 7.5 days of life. In our study, males were more affected than females and the male to female ratio was 2.38:1. The difference between the affected males and females was also statistically highly significant $(\mathrm{p}=.00013)$.

The major risk factors identified in the present study were prior use of antibiotics (100\%), 
intravenous catheterization (100\%), low birth weight $(81.82 \%)$ and prematurity $(75 \%)$. Other associated risk factors were referred cases from outside $(47.72 \%)$, prior prophylactic antifungal use (29.50\%), mechanical ventilation $(22.72 \%)$ and surgical interventions (4.54\%). These findings are consistent with many other studies from different regions of India. ${ }^{[4,7,13,14]}$ The hands of health care workers (HCWs) and environmental surfaces have also been recognised as reservoirs for nosocomial Candida infection. Prolonged use of antibiotics may suppress the bacterial flora and also result in development of refractory candidemia. Use of multiple indwelling devices (catheters, endotracheal tube) may cause break in skin/ mucosal integrity and predispose these sites for colonization/ infection by Candida spp. Candida spp. are very egregious to their capacity to attach with foreign materials and result in biofilm formation, that may be associated with higher rate of candidemia.

Among the maternal risk factors, vaginal delivery $(52.27 \%)$ was found to be most important risk factor, followed by $\mathrm{H} / \mathrm{o}$ intrapartum use of antibiotics, $\mathrm{H} / \mathrm{o}$ foul smelling liquor, $\mathrm{H} / \mathrm{o}$ prolonged rupture of membranes and H/o prolonged labour. This is consistent with findings of Chen et al., ${ }^{[15]}$, Wadile et al. ${ }^{[4]}$ and Hammoud et al., ${ }^{[16]}$ Vaginal delivery may contribute to neonatal candidemia due to vertical transmission from maternal vaginal flora and also due to hands of healthcare workers.

Thrombocytopenia may be a specific marker for fungal sepsis. In our study, it was found in $63.6 \%$ neonates, that is comparable to Ariff et al. ${ }^{[17]}$ However Yunas et al reported $80 \%$ incidence of thrombocytopenia in their study. ${ }^{[18]}$

The crude mortality rate in our study due was $36.36 \%$, (Table 5) which was lower than the observation of Femitha $\mathrm{P}$ et al. ${ }^{[19]}$

In conclusion the since, Candida spp. are assuming an increasingly important role in nosocomial infections in neonates, preventive measures such as appropriate use of multiple invasive medical devices and a strict policy of antibiotic use should be implemented to decrease Candida colonization/infection rates. Meticulous attention should be paid to hand hygiene practices, use of sterile alcohol swabs and intensive housekeeping routine to ensure proper asepsis.

\section{References}

Ariff S, Saleem AF, Soofi SB, Sajjad R (2011). Clinical spectrum and outcomes of neonatal candidiasis in a tertiary care hospital in Karachi, Pakistan. J Infect Dev Ctries 5: 216-223

Baley JE, Kliegman RM, Fanaroff AA. Disseminated fungal infections in Verylow-birth-weight infants: Clinical manifestations and epidemiology. Pediatrics. 1984; 73(2): 144-52.

Basu S, Kumar R, Tilak R, Kumar A. Candida blood stream infections in neonates: Experience from A Tertiary Care Teaching Hospital of Central India. Indian Pediatr. 2017; 54(7): 5569.

Basu S, Kumar R, Tilak R, Kumar A. Candida blood stream infections in neonates: Experience from A Tertiary Care Teaching Hospital of Central India. Indian Pediatr. 2017; 54(7): 5569.

Benjamin DK Jr, Stoll BJ, Gantz MG, Walsh MC, Sánchez PJ, Das A, et al., Neonatal candidiasis: epidemiology, risk factors and clinical judgment. Pediatrics. 2010; 126(4): 865-73.

Caggiano G, Lovero G, Giglio OD, Barbuti $\mathrm{G}$, Montagna $\mathrm{O}$, Laforgia $\mathrm{N}$, et al., Candidemia in the Neonatal Intensive Care Unit: A Retrospective, 
Observational Survey and Analysis of Literature Data. BioMed Res Int. 2017; 7901763: 1-12.

Chen J, Jiang Y, Wei B, Ding Y, Shaolin Xu, Qin $\mathrm{P}$, et al., Epidemiology of and risk factors for neonatal candidemia at a tertiary care hospital in western China. BMC Infect Dis. 2016; 16: 700.

Femitha P, Joy R, Adhisivam B, Bhat BV, Prasad K, Gane BD, et al., Candidemia in neonatal ICU- experience from a tertiary care hospital. Curr Pediatr Res. 2013; 17(1): 44-8.

Fridkin SK, Kaufman D, Edwards JR, Shetty $\mathrm{S}$, Horan T. Changing incidence of Candida bloodstream infections among NICU patients in the United States: 1995-2004. Pediatrics. 2006; 117(5): 1680-7.

Goel N, Ranjan PK, Aggarwal R, Chaudhary U, Sanjeev N. Emergence of Non albicans Candida in Neonatal Septicemia and Antifungal Susceptibility from a Tertiary Care Centre. J Lab Physicians. 2009; 1(2): 53-5.

Hornik CP, Fort P, Clark RH, Watt K, Benjamin DK Jr, Smith PB, et al., Early and late onset sepsis in very low birth weight infants from a large group of neonatal intensive care units. Early Hum Dev. 2012; 88(2): 69-74.

Juyal D, Sharma M, Pal S, Rathaur VK, Sharma N. Emergence of Non Albicans Candida Species in Neonatal Candidemia. N Am J Med Sci. 2013;
5(9): 541-5.

Kaufman D, Fairchild KD. Clinical microbiology of bacterial and fungal sepsis in very low birth weight infants. Clin Microbiol Rev. 2004; 17(3): 63880.

Lee BE, Cheung PY, Robinson JL, Evanochko C, Robertson CM. Comparative study of mortality and morbidity in premature infants (Birth Weight, 1,250 g) with Candidemia or Candidal Meningitis. Clin Infect Dis. 1998; 27(3): 559-65.

Sardana V, Pandey A, Madan M, Goel SP, Asthana AK. Neonatal candidemia: A changing trend. Indian $\mathbf{J}$ Pathol Microbiol. 2012; 55(1): 132-3.

Simonsen KA, Anderson-Berry AL, Delair SF, Davies HD. Early onset neonatal sepsis. Clin Microbiol Rev. 2014; 27(1): 21-47.

Wadile RG, Bhate VM. Study of clinical spectrum and risk factors of neonatal candidemia. Indian J Pathol Microbiol. 2015; 58(4): 472-4.

Yadav S, Dahiya S, Budhani D. Candidemia in neonatal intensive care unit: a cause of concern. Int J Res Med Sci. 2017; 5(5): 2165-7.

Yunus M, Agarwal V, Tomer P, Gupta P, Upadhyay A. Epidemiology, clinical spectrum and outcomes of fungal sepsis in neonates in neonatal intensive care unit: a prospective observational study. Int J of Cont Med Res 2018; 5(1): 1-5.

\section{How to cite this article:}

Baby, Perbhat Kansal, Neerja Jindal, Renu Bansal and Sameer Singh Faujdar. 2021. Study of Epidemiology, Risk Factors and Clinical Spectrum for Neonatal Candidemia at Tertiary Care Hospital in North India. Int.J.Curr.Microbiol.App.Sci. 10(01): 264-270. doi: https://doi.org/10.20546/ijcmas.2021.1001.032 